\title{
Effect of hydraulic parameters on sediment transport capacity in overland flow over erodible beds
}

\author{
M. Ali ${ }^{1}$, G. Sterk ${ }^{2}$, M. Seeger ${ }^{1}$, M. Boersema ${ }^{3}$, and P. Peters ${ }^{1}$ \\ ${ }^{1}$ Land Degradation and Development Group, Wageningen University, Wageningen, The Netherlands \\ ${ }^{2}$ Department of Physical Geography, Utrecht University, Utrecht, The Netherlands \\ ${ }^{3}$ Hydrology and Quantitative Water Management Group, Wageningen University, Wageningen, The Netherlands
}

Correspondence to: M. Ali (mazhar.ali@wur.nl)

Received: 21 June 2011 - Published in Hydrol. Earth Syst. Sci. Discuss.: 14 July 2011

Revised: 19 December 2011 - Accepted: 22 January 2012 - Published: 27 February 2012

\begin{abstract}
Sediment transport is an important component of the soil erosion process, which depends on several hydraulic parameters like unit discharge, mean flow velocity, and slope gradient. In most of the previous studies, the impact of these hydraulic parameters on transport capacity was studied for non-erodible bed conditions. Hence, this study aimed to examine the influence of unit discharge, mean flow velocity and slope gradient on sediment transport capacity for erodible beds and also to investigate the relationship between transport capacity and composite force predictors, i.e. shear stress, stream power, unit stream power and effective stream power. In order to accomplish the objectives, experiments were carried out in a $3.0 \mathrm{~m}$ long and $0.5 \mathrm{~m}$ wide flume using four well sorted sands $(0.230,0.536,0.719,1.022 \mathrm{~mm})$. Unit discharges ranging from 0.07 to $2.07 \times 10^{-3} \mathrm{~m}^{2} \mathrm{~s}^{-1}$ were simulated inside the flume at four slopes (5.2, 8.7, 13.2 and $17.6 \%$ ) to analyze their impact on sediment transport rate. The sediment transport rate measured at the bottom end of the flume by taking water and sediment samples was considered equal to sediment transport capacity, because the selected flume length of $3.0 \mathrm{~m}$ was found sufficient to reach the transport capacity. The experimental result reveals that the slope gradient has a stronger impact on transport capacity than unit discharge and mean flow velocity due to the fact that the tangential component of gravity force increases with slope gradient. Our results show that unit stream power is an optimal composite force predictor for estimating transport capacity. Stream power and effective stream power can also be successfully related to the transport capacity, however the relations are strongly dependent on grain size. Shear stress showed poor performance, because part of shear stress is dissipated by bed irregularities, bed form evolution and
\end{abstract}

sediment detachment. An empirical transport capacity equation was derived, which illustrates that transport capacity can be predicted from median grain size, total discharge and slope gradient.

\section{Introduction}

Soil erosion has become a major global environmental problem (Lal, 1998). Several process-based soil erosion models have been developed to estimate sediment yield at the catchment scale (KINEROS2, Smith et al., 1995; LISEM, De Roo et al., 1996; EUROSEM; Morgan et al., 1998; WEPP, Flanagan et al., 2001). Soil erosion is a combination of detachment and transport of sediment particles. An accurate estimation of these processes is the main objective of process-based models. Under overland flow conditions, sediment detachment rate depends on the potential of rainfall and a thin layer of overland flow to detach soil particles from the soil matrix as well as on the resistance of the soil against detachment. The potential of rainfall and thin layer of flow is separately ascertained by using different equations during soil erosion modelling (e.g. Foster, 1982; Elliot and Laflen, 1993; Wei et al., 2009). Here in this study, we are dealing with the potential of overland flow. Most of the existing models estimate sediment detachment rate of flowing water by using the concept of Foster and Meyer (1972). According to this concept, the detachment rate is calculated as the difference between the sediment transport capacity and actual sediment load. Hence, sediment transport capacity plays a pivotal role in the physical description of soil erosion processes. 
Sediment transport capacity is defined as the maximum sediment load that a particular discharge can transport at a certain slope (Merten et al., 2001). During the last three decades, several efforts have been made to analyze the influence of different hydraulic parameters on transport capacity, such as unit discharge, mean flow velocity, and slope gradient (Beasley and Huggins, 1982; Julien and Simons, 1985; Govers and Rauws, 1986; Finkner et al., 1989; Govers, 1990, 1992; Guy et al., 1990; Everaert, 1991; Abrahams and Li, 1998; Jayawardena and Bhuiyan, 1999; Prosser and Rustomji, 2000; Abrahams et al., 2001; Zhang et al., 2009). These variables were mostly considered for the quantification of sediment transport capacity under overland flow conditions because they can be easily measured in the field and also have a pronounced impact on transport capacity. It is generally known that transport capacity increases with the increase of unit discharge, slope gradient, and mean flow velocity, since the energy exerted by a certain discharge on the bed increases with these variables (Beasley and Huggins, 1982; Govers, 1990, 1992; Everaert, 1991; Zhang et al., 2009, 2010a). In comparison to river hydraulics, far less research has been done to quantify sediment transport under shallow flow on an eroding hillslope. The influence of these hydraulic parameters on sediment transport has mainly been studied using datasets obtained from flume experiments with non-erodible beds. For erodible bed experiments, previous researchers usually assumed that their selected flume length was adequate to reach the transport capacity (e.g. Govers, 1990; Everaert, 1991). But qualitative and quantitative information about the spatial variation in sediment load is needed to verify this assumption.

The relationship between transport capacity and unit discharge has often been studied, and previous research has made it clear that this relationship is always dependent on slope (Beasley and Huggins, 1982; Julien and Simons, 1985; Govers and Rauws, 1986; Govers, 1990; Everaert, 1991; Jayawardena and Bhuiyan, 1999; Prosser and Rustomji, 2000; Lei et al., 2001; Zhang et al., 2009). However, the effect of unit discharge and slope on transport capacity varies from erodible to non-erodible bed conditions (Gover, 1990; Everaert, 1991; Zhang et al., 2009), probably due to the fact that, for the same hydraulic and sediment conditions, the roughness of erodible beds is always higher than that of nonerodible beds (Hu and Abrahams, 2006). Govers (1990) and Everaert (1991) found, in different studies, that for erodible beds the effect of slope on transport capacity is higher than the effect of unit discharge. Contrasting with this, the nonerodible bed experiments of Zhang et al. (2009) revealed that transport capacity is more susceptible to unit discharge as compared to slope. This raises questions about the applicability of information obtained from non-erodible beds for the development of sediment transport equations to be used in soil erosion models.

The influence of mean flow velocity on transport capacity has been studied mainly under non-erodible bed conditions
(Guy et al., 1990; Abrahams and Li, 1998; Zhang et al., 2009, 2010a,b). Guy et al. (1990) found that transport capacity increases as mean flow velocity increases because mean flow velocity consistently increases with slope. Zhang et al. (2009) even reported a linear increase of transport capacity with increasing mean flow velocity for non-erodible beds. Again, contradicting results were found under erodible bed conditions (Govers, 1990; Nearing et al., 1997, 1999; Takken et al., 1998; Gimenez and Govers, 2001), where the influence of slope on flow velocity was non-significant and, consequently, flow velocity had no clear influence on sediment transport capacity. As a result, it is clear that there is a need to comprehensively study the influence of different hydraulic parameters on sediment transport capacity.

Hydraulic variables can be combined in different ways to form composite force predictors (Duboys, 1879; Bagnold, 1966; Yang, 1972; Govers, 1990). Accordingly, different composite force predictors were used to estimate transport capacity of overland flow, i.e. shear stress, stream power, unit stream power, and effective stream power (Yang, 1972; Moore and Burch, 1986; Govers and Rauws, 1986; Lu et al., 1989; Govers, 1990, 1992; Everaert, 1991; Jayawardena and Bhuiyan, 1999; Prosser and Rustomji, 2000; Abrahams et al., 2001; Zhang et al., 2009). But widely varying results were obtained because the performance of composite force predictors were tested under different ranges of morphologic conditions. Govers and Rauws (1986) concluded that shear stress is not a good predictor for estimating transport capacity under erodible bed conditions, because an important component of the shear stress (i.e. form shear stress) may not be actively used for sediment transport, but could be preferentially consumed on sediment detachment and bed form evolution. Therefore, they suggested the use of grain shear stress (the part of shear stress consumed on individual grains) and unit stream power concepts to predict transport capacity on erodible beds. However, later results from Govers (1990) contradict the recommendations of Govers and Rauws (1986), showing that shear stress can be used to estimate transport capacity under erodible beds. In addition, the experimental results of Zhang et al. (2009) also depicted that transport capacity was well predicted by shear stress for non-erodible bed conditions.

The influence of unit discharge and mean flow velocity on transport capacity under erodible bed conditions is still unclear and needs to be further examined in order to get a better understanding of the processes involved in sediment transport by overland flow. In addition, the selection of a suitable composite predictor for the estimation of transport capacity is also still uncertain. Therefore, the objectives of this research were (i) to study the effect of unit discharge, mean flow velocity and slope gradient on sediment transport capacity and how these relations vary in the presence and absence of bed irregularities; and (ii) to evaluate the potential of different composite force predictors for the estimation of transport capacity under overland flow conditions. Fundamental 
for addressing these objectives is knowing if the selected experimental setup is sufficient for reaching the transport capacity. To tackle these objectives, an experiment on erodible beds was designed with variable slopes, discharges and different non-cohesive bed materials.

\section{Materials and methods}

For this study, a $3.0 \mathrm{~m}$ long and $0.5 \mathrm{~m}$ wide rectangular flume with a wooden floor and one sided plexiglass wall was constructed. The experimental set-up was similar to the one described by Ali et al. (2012). In order to abridge the edge effects, a piece of wood (length $=0.20$, width $=0.50$, height $=0.04 \mathrm{~m}$, "stopper") was fixed at the upper end of the flume and a second stopper (length $=0.10$, width $=0.50$, height $=0.04 \mathrm{~m}$ ) was fixed at the lower end (Fig. 1). The upper stopper also allows the water to enter into the test section from the head tank, avoiding erosion and causing uniform spread of the applied discharge across the flume width. The length of the lower stopper (i.e. $0.10 \mathrm{~m}$ ) was selected to allow passing of the water and sediment mixture without causing any serious deposition. Tap water was used to conduct the experiments, which entered into the flume from a head tank. The rate of flow into the head tank was controlled by a valve and measured with a calibrated flow-meter at the inlet pipe. The flow-meter was connected to a data-logger and computer for continuous monitoring of the inflow rate. The applied unit discharge rates ranged from 0.07 to $2.07 \times 10^{-3} \mathrm{~m}^{2} \mathrm{~s}^{-1}$.

In order to study the variation of sediment transport capacity with grain size, four well sorted non-cohesive medium to very coarse sands with median grain size $\left(D_{50}\right)$ equal to $0.233,0.536,0.719$, and $1.022 \mathrm{~mm}$ and their bulk density equal to $1600 \mathrm{~kg} \mathrm{~m}^{-3}$ were used. Non-cohesive sands were selected since they ignore the impact of aggregate stability on sediment transport capacity. Aggregates would also have a very variable size and density, introducing with this more parameters which cannot be recorded during the experiments. Moreover, with these types of non-cohesive sands, sediment transport capacity can be achieved in such a small flume length, i.e. 3.0 m (Govers, 1990, 1992; Everaert, 1991). Flume experiments were carried out using medium to coarse sands, because majority of existing transport capacity equations were derived either for fine materials ranging from clay to fine sands (Govers and Rauws, 1986; Govers, 1990, 1992; Everaert, 1991) or for non-erodible beds (Guy et al., 1990: Abrahams and Li, 1998; Abrahams et al., 2001; Zhang et al., 2009). Prior to each experiment, the test section was filled with a $0.04 \mathrm{~m}$ thick layer of sediment and saturated with water. The contact area between the upper stopper and sand layer was covered with a piece of artificial grass carpet in order to dissipate the flow energy of the inflowing water. However, sudden high rates of erosion could not be fully prevented. For the experiments, the flume bed was adjusted to four slope gradients $(5.2,8.7,13.2$ and

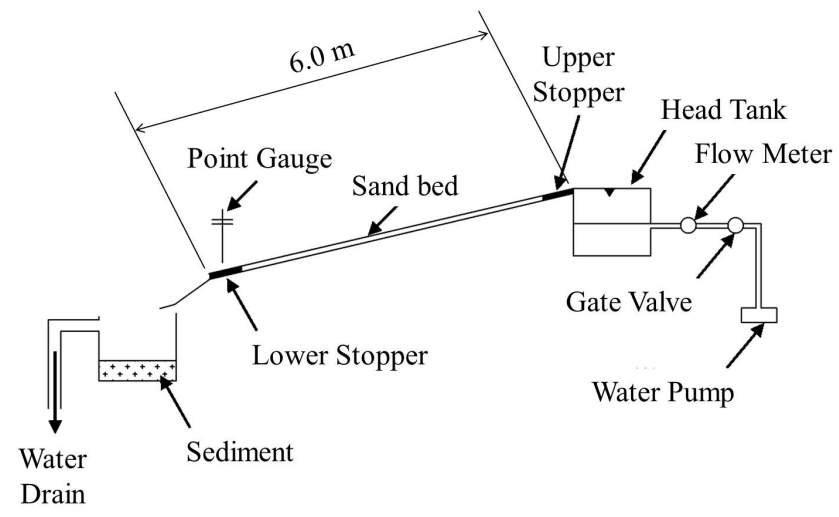

Fig. 1. Experimental flume utilized for sediment transport capacity measurements in relation to hydraulic and sediment parameters.

$17.6 \%$ ), to analyse the impact of slope on sediment transport capacity. Before each experiment, test runs were carried out to adjust the duration of the inflow for each combination of applied unit discharge, slope gradient and sediment type. As a result of these test runs, the time to conduct experiments ranged between 5 and $30 \mathrm{~min}$. Each experimental run was repeated once to ensure the results, resulting in 81 experiments. For each selected sand, different ranges of unit discharges were applied under four slope gradients, i.e. 5.2, 8.7, 13.2 and $17.6 \%$. Because the current experiments were carried out with $0.04 \mathrm{~m}$ thick layer of sand under erodible bed conditions, higher rates of unit discharges were used for coarse sand (i.e. $1.022 \mathrm{~mm}$ ) as compared to fine sand (i.e. $0.233 \mathrm{~mm}$ ). The summary of experimental data is presented in Table 1.

As flow depths are usually hard to assess under overland flow conditions on a changing bed due to the unsteadiness of the water and bed surface, two point gauges with an accuracy of $0.1 \mathrm{~mm}$ were hung on a wooden frame above the lower stopper of the flume, directly downstream of the sand bed. The mean flow depth was calculated by averaging of the measurements taken from both gauges.

Mean flow velocity is difficult to measure under interrill and rill erosion due to spatial variation of bed geometry and limited flow depth (Jayawardena and Bhuiyan, 1999). The conversion of surface flow velocity measurements into mean flow velocity has also become a challenge because of the selection of a suitable correction factor (Dunkerley, 2001). Hence in this study, mean flow velocities were estimated using the equation derived by Ali et al. (2012) for the same flume:

$$
\begin{aligned}
\log (U) & =0.645+0.506 \log (Q)-0.172 \log \left(D_{50}\right) \\
R^{2} & =0.89
\end{aligned}
$$

where $U\left(\mathrm{~m} \mathrm{~s}^{-1}\right)$ is the mean flow velocity, $Q\left(\mathrm{~m}^{3} \mathrm{~s}^{-1}\right)$ is the total discharge, and $D_{50}(\mathrm{~m})$ is the median grain diameter of the bed material. 
Table 1. Experimental data.

\begin{tabular}{|c|c|c|c|c|c|}
\hline Run No. & $\begin{array}{c}D_{50} \\
(\mathrm{~mm})\end{array}$ & $\begin{array}{r}\text { Slope } \\
(\%)\end{array}$ & $\begin{array}{l}\text { Unit discharge } \\
\left(10^{-3} \mathrm{~m}^{2} \mathrm{~s}^{-1}\right)\end{array}$ & $\begin{array}{l}\text { Measured } \\
\text { flow depth } \\
\quad(\mathrm{m})\end{array}$ & $\begin{array}{l}\text { Measured sediment } \\
\text { transport capacity } \\
\quad\left(\mathrm{kg} \mathrm{m}^{-1} \mathrm{~s}^{-1}\right)\end{array}$ \\
\hline 1 & 0.230 & 5.2 & 0.17 & 0.00120 & 0.0008 \\
\hline 2 & & & & 0.00120 & 0.0009 \\
\hline 3 & & & 0.33 & 0.00140 & 0.0068 \\
\hline 4 & & & & 0.00140 & 0.0062 \\
\hline 5 & & & 0.67 & 0.00200 & 0.0229 \\
\hline 6 & & & & 0.00200 & 0.0312 \\
\hline 7 & & 8.7 & 0.17 & 0.00115 & 0.0099 \\
\hline 8 & & & & 0.00115 & 0.0076 \\
\hline 9 & & & 0.33 & 0.00155 & 0.0314 \\
\hline 10 & & & & 0.00155 & 0.0373 \\
\hline 11 & & & 0.50 & 0.00160 & 0.0450 \\
\hline 12 & & & & 0.00160 & 0.0601 \\
\hline 13 & & 13.2 & 0.17 & 0.00115 & 0.0195 \\
\hline 14 & & & 0.33 & 0.00140 & 0.0677 \\
\hline 15 & & & 0.50 & 0.00205 & 0.1337 \\
\hline 16 & & 17.6 & 0.07 & 0.00085 & 0.0145 \\
\hline 17 & & & & 0.00085 & 0.0175 \\
\hline 18 & & & 0.17 & 0.00100 & 0.0544 \\
\hline 19 & & & & 0.00100 & 0.0505 \\
\hline 20 & 0.536 & 5.2 & 0.17 & 0.00093 & 0.0014 \\
\hline 21 & & & & 0.00093 & 0.0014 \\
\hline 22 & & & 0.33 & 0.00160 & 0.0063 \\
\hline 23 & & & & 0.00160 & 0.0067 \\
\hline 24 & & & 0.67 & 0.00260 & 0.0162 \\
\hline 25 & & & & 0.00260 & 0.0204 \\
\hline 26 & & 8.7 & 0.17 & 0.000895 & 0.0074 \\
\hline 27 & & & & 0.000895 & 0.0065 \\
\hline 28 & & & 0.33 & 0.00150 & 0.0228 \\
\hline 29 & & & & 0.00150 & 0.0238 \\
\hline 30 & & & 0.50 & 0.00220 & 0.0336 \\
\hline 31 & & & & 0.00220 & 0.0361 \\
\hline 32 & & 13.2 & 0.17 & 0.00100 & 0.0229 \\
\hline 33 & & & & 0.00100 & 0.0189 \\
\hline 34 & & & 0.33 & 0.00150 & 0.0587 \\
\hline 35 & & & & 0.00150 & 0.0519 \\
\hline 36 & & & 0.50 & 0.00180 & 0.0952 \\
\hline 37 & & & & 0.00180 & 0.0890 \\
\hline 38 & & 17.6 & 0.07 & 0.00097 & 0.0086 \\
\hline 39 & & & & 0.00097 & 0.0095 \\
\hline 40 & & & 0.17 & 0.00100 & 0.0347 \\
\hline 41 & & & & 0.00100 & 0.0438 \\
\hline 42 & 0.719 & 5.2 & 0.33 & 0.00185 & 0.0064 \\
\hline 43 & & & & 0.00185 & 0.0071 \\
\hline 44 & & & 1.00 & 0.00330 & 0.0354 \\
\hline 45 & & & & 0.00330 & 0.0278 \\
\hline 46 & & & 2.07 & 0.00515 & 0.0838 \\
\hline 47 & & & & 0.00515 & 0.0657 \\
\hline 48 & & 8.7 & 0.17 & 0.00115 & 0.0084 \\
\hline 49 & & & & 0.00115 & 0.0066 \\
\hline 50 & & & 0.33 & 0.00125 & 0.0236 \\
\hline 51 & & & & 0.00125 & 0.0249 \\
\hline 52 & & & 1.00 & 0.00295 & 0.0870 \\
\hline 53 & & & & 0.00295 & 0.0888 \\
\hline
\end{tabular}


Table 1. Continued.

\begin{tabular}{|c|c|c|c|c|c|}
\hline Run No. & $\begin{array}{c}D_{50} \\
(\mathrm{~mm})\end{array}$ & $\begin{array}{r}\text { Slope } \\
(\%)\end{array}$ & $\begin{array}{l}\text { Unit discharge } \\
\left(10^{-3} \mathrm{~m}^{2} \mathrm{~s}^{-1}\right)\end{array}$ & $\begin{array}{l}\text { Measured } \\
\text { flow depth } \\
\quad(\mathrm{m})\end{array}$ & $\begin{array}{l}\text { Measured sediment } \\
\text { transport capacity } \\
\quad\left(\mathrm{kg} \mathrm{m}^{-1} \mathrm{~s}^{-1}\right)\end{array}$ \\
\hline 54 & & 13.2 & 0.17 & 0.00115 & 0.0192 \\
\hline 55 & & & 0.33 & 0.00170 & 0.0491 \\
\hline 56 & & & 0.50 & 0.00180 & 0.0911 \\
\hline 57 & & 17.6 & 0.07 & 0.00075 & 0.0073 \\
\hline 58 & & & & 0.00075 & 0.0072 \\
\hline 59 & & & 0.17 & 0.00135 & 0.0365 \\
\hline 60 & & & & 0.00135 & 0.0308 \\
\hline 61 & 1.022 & 5.2 & 0.33 & 0.00195 & 0.0045 \\
\hline 62 & & & & 0.00195 & 0.0044 \\
\hline 63 & & & 1.00 & 0.00390 & 0.0252 \\
\hline 64 & & & & 0.00390 & 0.0260 \\
\hline 65 & & & 2.07 & 0.00565 & 0.0670 \\
\hline 66 & & & & 0.00565 & 0.0651 \\
\hline 67 & & 8.7 & 0.17 & 0.00125 & 0.0042 \\
\hline 68 & & & & 0.00125 & 0.0043 \\
\hline 69 & & & 0.33 & 0.00195 & 0.0173 \\
\hline 70 & & & & 0.00195 & 0.0179 \\
\hline 71 & & & 1.00 & 0.00305 & 0.1063 \\
\hline 72 & & & & 0.00305 & 0.0784 \\
\hline 73 & & 13.2 & 0.17 & 0.00120 & 0.0118 \\
\hline 74 & & & 0.33 & 0.00175 & 0.0437 \\
\hline 75 & & & 0.50 & 0.00250 & 0.0794 \\
\hline 76 & & 17.6 & 0.07 & 0.00120 & 0.0018 \\
\hline 77 & & & & 0.00120 & 0.0020 \\
\hline 78 & & & 0.17 & 0.00150 & 0.0170 \\
\hline 79 & & & & 0.00150 & 0.0187 \\
\hline 80 & & & 0.33 & 0.00195 & 0.0946 \\
\hline 81 & & & & 0.00195 & 0.0976 \\
\hline
\end{tabular}

During each run, a mixture of water and sediment was collected in a container at the bottom end of the flume at regular time intervals (1-5 min). Five to six samples were taken during each run, depending on the duration of the run. Supernatant water was poured out from the sample when the sediment settled down on the bed of the container. The remaining wet sediment was oven dried at $105^{\circ} \mathrm{C}$ for $12 \mathrm{~h}$, then weighed to determine the dry sediment weight. Average dry sediment weight was calculated by taking the mean dry weight of all sediment samples taken during each run. The sediment transport rate was determined by dividing the average dry sediment weight with run duration and flume width (i.e. $0.50 \mathrm{~m}$ ).

In order to quantify the sediment budget along the flume length, the bed of the flume was scanned with a surface laser scanner for a selected number (45) of runs, before and after overland flow simulation. The elevation accuracy of the scanner is $1.0 \mathrm{~mm}$. Using the data obtained from the laser scanner, detailed topographic maps with a horizontal spatial resolution of $5.0 \mathrm{~mm}$ were constructed using the triangulation method in the SURFER software package (Golden
Software, 2004). Starting at $0.74 \mathrm{~m}$ below the upper stopper, $2.0 \mathrm{~m}$ of the flume length were scanned. The scanned area of the flume was divided into twenty equivalent slices of $100.0 \mathrm{~mm}$ length to study the sediment budget along the flume length. For each slice, the weight of the eroded sediment was calculated multiplying eroded sediment volume by bulk density (i.e. $1600 \mathrm{~kg} \mathrm{~m}^{-3}$ ). The calculated weight of the eroded sediment was divided by duration of an experiment and area of a slice (i.e. $500 \mathrm{~cm}^{2}$ ) to estimate the sediment detachment or deposition rate along the flume length. This was done after each $100.0 \mathrm{~mm}$ interval for each combination of discharge, slope, and grain size.

The calculated sediment budget along the flume length was used to corroborate the hypothesis that a flume length of $3.0 \mathrm{~m}$ is adequate to reach the transport capacity for the given conditions of flow, slope and sediment type, for which the experiments were conducted. The effects of unit discharge, mean flow velocity and slope gradient on transport capacity were analysed graphically.

Prediction of sediment transport capacity was done by regression analysis in order to identify an optimal predictor 
among shear stress, stream power, unit stream power and effective stream power. Shear stress is defined as the force applied by flowing water on the soil surface per unit bed area (Duboys, 1879):

$\tau=\rho u_{*}^{2}$

where $\tau\left(\mathrm{N} \mathrm{m}^{-2}\right)$ is the shear stress, $\rho\left(\mathrm{kg} \mathrm{m}^{-3}\right)$ is the density of water, $u_{*}=\sqrt{g R S}\left(\mathrm{~m} \mathrm{~s}^{-1}\right)$ is the shear velocity, $g\left(\mathrm{~m} \mathrm{~s}^{-2}\right)$ is the gravitational acceleration, $R(\mathrm{~m})$ is the hydraulic radius, which is considered equal to the flow depth $(h)$, as flow width is much greater than flow depth under shallow overland flow conditions, and $S\left(\mathrm{~m} \mathrm{~m}^{-1}\right)$ is the slope gradient. The stream power concept was introduced by Bagnold (1966) who assumed that the sediment transport rate is a function of time rate of potential energy expenditure per unit bed area:

$\omega=\tau U$

where $\omega\left(\mathrm{J} \mathrm{m}^{-2} \mathrm{~s}^{-1}\right)$ is the stream power, and $U\left(\mathrm{~m} \mathrm{~s}^{-1}\right)$ is the mean flow velocity. Yang (1972) assumed that the sediment transport rate is a function of time rate of potential energy expenditure per unit weight of water:

$\omega_{\mathrm{u}}=U S$

where $\omega_{\mathrm{u}}\left(\mathrm{m} \mathrm{s}^{-1}\right)$ is the unit stream power. Effective stream power is fundamentally based on the shear stress concept (Govers, 1990):

$\omega_{\mathrm{eff}}=\frac{(\tau U)^{1.5}}{h^{0.67}}$

where $\omega_{\text {eff }}\left(\mathrm{N}^{1.5} \mathrm{~s}^{-1.5} \mathrm{~m}^{-2.17}\right)$ is the effective stream power.

In order to assess the bias and the standard errors associated with predictions of the best performing composite force predictor, a jack-knife technique was adopted. The main reason for using the jack-knife technique is that the derived equation is not validated using exactly the same dataset that was utilised to derive the equation. In this technique, one observation is held out and the remaining observations are used to fit the coefficients. Then, the fitted model is used to make the prediction for the held out observation. Model bias and standard errors were described by a statistical term "error", which is calculated as the difference between the observed and predicted values of transport capacity. The error has a minimum value of 0 and the values close to 0 indicates better estimation.

\section{Results and discussion}

The measured sediment transport capacities for the selected sands, slope gradients, and unit discharges are given in Table 1. The transport capacities of the four sands varied from 0.0008 to $0.1337 \mathrm{~kg} \mathrm{~m}^{-1} \mathrm{~s}^{-1}$ (Table 1), and are in approximately the same range as measured by Govers (1990) and
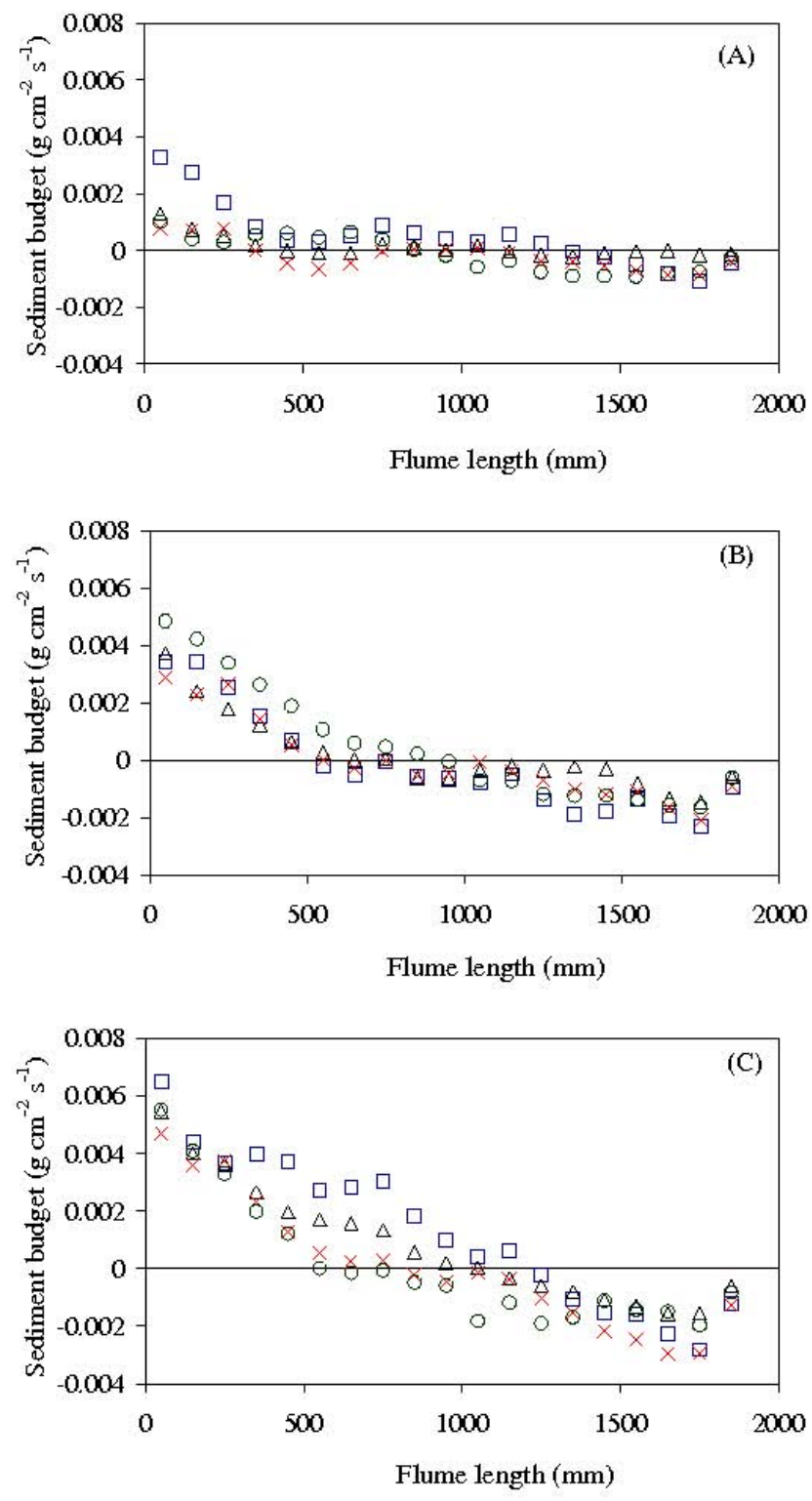

$\mathrm{D}_{50}(\mathrm{~mm}) \sqsupset 0.230 \quad \Delta 0.536 \times 0.719 \quad \bigcirc 1.022$

Fig. 2. Sediment budget along the flume length corresponding to unit discharges of (A) 0.17 , (B) 0.33 and (C) $0.50 \times 10^{-3} \mathrm{~m}^{2} \mathrm{~s}^{-1}$ at a slope of $13.2 \%$ for different grain size classes.

Everaert (1991) for similar ranges of hydraulic and sediment conditions. During our experiments, the calculated values of the Reynolds number ranged from 253 to 7916 , and the Froude number ranged from 0.7 to 2.3 , which implies that the flow conditions inside the flume ranged from laminar to turbulent and from subcritical to supercritical, respectively.

\subsection{Sediment budget along the flume length}

Figure 2 shows the variation in sediment budget along the flume length for the three unit discharges $(0.17,0.33$ and 
$0.50 \times 10^{-3} \mathrm{~m}^{2} \mathrm{~s}^{-1}$ ) at a slope of $13.2 \%$ for four sands. The budgets were calculated from the laser scanner data. It is clear that the detachment rate is at a maximum level at the upper side of the flume where clean water enters and decreases with distance for each of the three applied unit discharges. This is due to the fact that the flow energy, which is required to detach sediment particles from the soil mass, decreases with the increase of sediment load (Lei et al., 1998; Merten et al., 2001). On the other hand, deposition rate increases progressively along the flume length. After a certain distance, the system attained an equilibrium between sediment detachment and deposition, so the net detachment became zero and sediment load achieved its steady (maximum) value (Fig. 2a-c). According to Foster and Meyer (1972), the sediment transport rate reaches its maximum (= transport capacity) when the detachment rate becomes zero. Therefore, the steady value of sediment load for a particular discharge and slope corresponded to the sediment transport capacity of the flowing water. Similar results were obtained from the other runs, which were carried out at 5.2, 8.7 and $17.6 \%$ slopes. Thus, the flume length of $3.0 \mathrm{~m}$ was found sufficient to reach the sediment transport capacity. As a result, the average sediment transport rate, measured at the bottom end of the flume by taking samples of water and sediment mixture during each experimental run, was assumed to represent the sediment transport capacity.

\subsection{Effect of unit flow rate and mean flow velocity on sediment transport capacity}

As shown in Fig. 3, the measured transport capacity increased with unit discharge. Moreover, slope also had a strong influence on the measured transport capacity. For instance, when simulating a unit discharge of $0.33 \times 10^{-3} \mathrm{~m}^{2} \mathrm{~s}^{-1}$, the measured value for transport capacity at a slope of $5.2 \%$ was $94 \%$ lower than the value obtained at a $17.6 \%$ slope (Fig. 3). The strong impact of slope on transport capacity can be explained by the generally known phenomenon that the tangential component of gravity force, which acts along the bed in a downstream direction, increases with slope (Chorley et al., 1984). This is likely to be the reason that the measured transport capacity was more sensitive to slope than to unit discharge for erodible beds. These results agree with others' findings (Beasley and Huggins, 1982; Govers and Rauws, 1986; Govers, 1990; Everaert, 1991), but contradict the results of Guy et al. (1987) and Zhang et al. (2009). The latter studies, conducted on fixed beds, ignored the dynamics of knickpoints, headcuts, scour hole, slumping of the rill walls, etc. as well as the variation in bed form, where unit discharge has more strong impact on transport capacity as compared to slope.

Under non-erodible beds, sediment transport capacity is anticipated to be over-predicted because (i) the available flow energy is preferentially used for sediment transport, but any excess energy could lead to the detachment of deposited

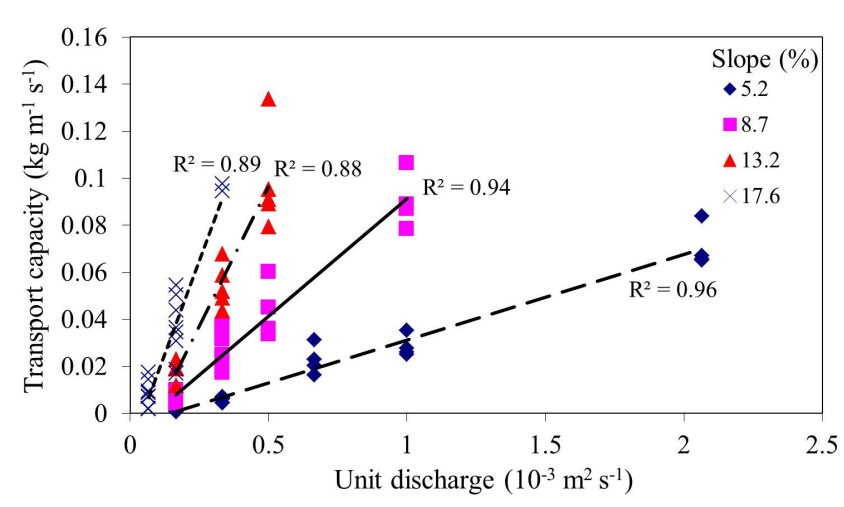

Fig. 3. Relationship between measured sediment transport capacity and unit discharge for different slope classes. All sediment types were included.

sediment; and (ii) the resistance of non-erodible beds is noticeably less than those of erodible beds (Gimenez and Govers, 2001; Hu and Abrahams, 2006; Zhang et al., 2010c). With erodible beds, on the other hand, irregularities increase with slope and slow down the water flow by reducing the local slope, whereby the transport capacity is reduced (Gimenez and Govers, 2001, 2002). The available flow energy under erodible bed conditions is not only used for transport of sediment, but is also greatly dissipated by the bed irregularities as well as the detachment of sediment (Gimenez and Govers, 2001, 2002).

Mean flow velocity is another important hydraulic parameter affecting sediment transport capacity, and depends on total discharge, median grain size, and bed geometry (Ali et al., 2012). Figure 4 shows that the transport capacity increased with the increase of mean flow velocity for each slope class. Again it is clearly illustrated that slope had a pronounced effect on the correlations between transport capacity and mean flow velocity. Experimental results revealed that transport capacity substantially increased with slope at a fixed mean flow velocity value (Fig. 4). For example, at a mean flow velocity of $0.18 \mathrm{~m} \mathrm{~s}^{-1}$, the measured values of transport capacity were $0.003 \mathrm{~kg} \mathrm{~m}^{-1} \mathrm{~s}^{-1}$ at $5.2 \%$ slope, and $0.095 \mathrm{~kg} \mathrm{~m}^{-1} \mathrm{~s}^{-1}$ at $17.6 \%$ slope, respectively (Fig. 4). This is due to the fact that the flow energy of a particular discharge substantially increases with slope, but a major part of the flow energy is dissipated for the detachment and transport of sediment instead of increasing flow velocity (Gimenez and Govers, 2002). However, Guy et al. (1990) and Zhang et al. (2009) found that the relationship between transport capacity and mean flow velocity was almost independent of slope. The possible reason for this contradiction is that under non-erodible beds, the mean flow velocity gradually increases with slope due to less variation in bed roughness (Foster et al., 1984; Abrahams et al., 1996; Gimenez and Govers, 2001; Zhang et al., 2009), while for erodible beds the mean flow velocity is almost independent of slope effect because bed morphology and roughness is dependent on both 


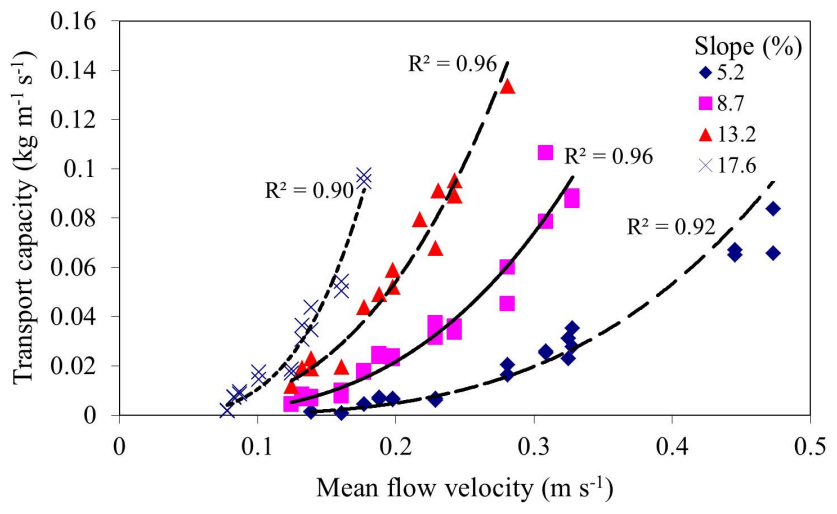

Fig. 4. Relationship between measured sediment transport capacity and mean flow velocity for different slope classes. All sediment types were included.

discharge and slope (Govers, 1992; Nearing et al., 1997, 1999; Takken et al., 1998; Gimenez and Govers, 2001). The impact of slope gradient on mean flow velocity was also found non-significant for the flow conditions that were used to conduct the current erodible bed flume experiments (Ali et al., 2012). Therefore, the theoretical concepts derived from non-erodible beds do not necessarily reflect erodible bed conditions, and their application on a natural hillslope may produce errors.

\subsection{Prediction of sediment transport capacity}

In previous studies composite force predictors have often been correlated with sediment transport capacity and most of the time it has been found that the relationship between transport capacity and a composite predictor can vary with grain size (Govers and Rauws, 1986; Govers, 1990; Everaert, 1991; Abrahams et al., 1998; Ferro, 1998; Jayawardena and Bhuiyan, 1999; Zhang et al., 2009). As it is expected that grain size also significantly affects the relationships between transport capacity and composite force predictors, in this study four types of sand were used to conduct the experiments.

Sediment transport capacity was modelled as a power function of composite force predictors, i.e. shear stress, stream power, unit stream power, and effective stream power by using the entire dataset of the four different grain sizes (Fig. 5). The best agreement $\left(R^{2}=0.87\right)$ with transport capacity was obtained using unit stream power (Fig. 5c). However, when a multiple linear regression analysis was used to estimate transport capacity as a function of unit stream power and grain size, it was not significantly affected by grain size $(p=0.197)$. The non-significant effect of grain size on the relationship between transport capacity and unit stream power was somewhat surprising, because grain size has been seen to have considerable effect on mean flow velocity (Ali et al., 2012). These results do agree with the findings of previous researchers (Govers and Rauws, 1986; Moore and Burch, 1986; Govers, 1990) in such a way that the unit stream power theory showed greatest potential for estimating transport capacity of overland flow under erodible beds. But they contradict earlier findings in the sense that the exponent of unit stream power was independent of grain size.

The regression analysis between transport capacity and unit stream power produced the following relationship:

$T_{\mathrm{c}}=2326.6 \omega_{\mathrm{u}}^{2.89} R^{2}=0.87$

where $T_{\mathrm{c}}\left(\mathrm{kg} \mathrm{m}^{-1} \mathrm{~s}^{-1}\right)$ is the sediment transport capacity and $\omega_{\mathrm{u}}\left(\mathrm{m} \mathrm{s}^{-1}\right)$ is the unit stream power.

The performance of shear stress was poor $\left(R^{2}=0.61\right)$ as compared to other composite predictors (Fig. 5a). The possible reason for its poor performance is that lower shear stress is needed to attain a certain value of transport capacity for fine sand (i.e. $0.230 \mathrm{~mm}$ ) as compared to coarse sand i.e. $1.022 \mathrm{~mm}$ (Fig. 5a). In a multiple linear regression analysis of shear stress and grain size to estimate transport capacity, the effect of grain size was significant $(p \ll 0.05)$. In general, transport capacity is expected to decrease with increasing surface roughness, since part of the momentum in overland flow is consumed by form roughness (Gimenez and Govers, 2002). Increasing surface roughness leads to increasing values of total shear stress. Therefore, total shear stress is a poor predictor for transport capacity, which is also consistent with the literature results (Govers and Rauws, 1986; Govers, 1992).

Stream power and effective stream power produced, when plotted against transport capacity, relatively lower scatter as compared to shear stress, thus both resulted in reasonable relationships with transport capacity (Fig. $5 b$ and d). Similar to the shear stress results, grain size had a significant impact $(p<0.05)$ on transport capacity in the multiple linear regression analysis, relating transport capacity to stream power or effective stream power and grain size using all data. Dependency of transport capacity on grain size in this case is due to the fact that both predictors are a function of shear stress. Several other researchers also found that the relationship between transport capacity and effective stream power is dependent on grain size (Govers, 1990; Everaert, 1991; Ferro, 1998). In contrast to shear stress, stream power is not affected by increasing surface roughness, while affective stream power and unit stream power decrease with increasing bed roughness (Gimenez and Govers, 2002). The latter finding might also explain the good performance of unit stream power and effective stream power.

In a previous study, it was found that the mean flow velocity on the erodible bed in the same flume could be well predicted from total discharge and median grain size (Eq. 1). Equation (1) can be written as:

$U=4.42 \frac{Q^{0.506}}{D_{50^{0.172}}}$ 

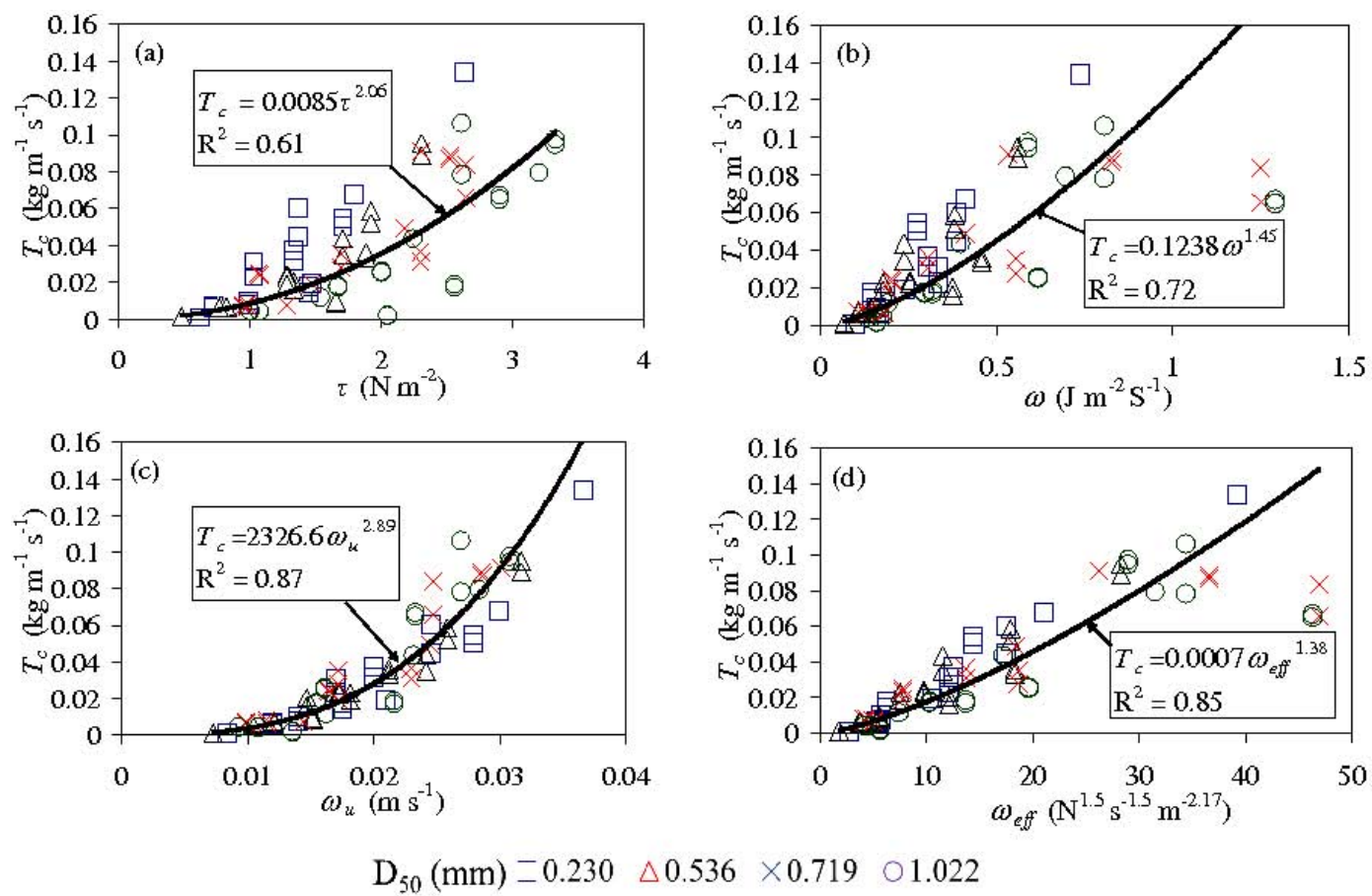

Fig. 5. Sediment transport capacity $\left(T_{\mathrm{c}}\right)$ as a function of (a) shear stress, $\tau$; (b) stream power, $\omega$; (c) unit stream power, $\omega_{\mathrm{u}}$; (d) effective stream power, $\omega_{\text {eff }}$ for four grain sizes.

where $U\left(\mathrm{~m} \mathrm{~s}^{-1}\right)$ is the mean flow velocity, $Q\left(\mathrm{~m}^{3} \mathrm{~s}^{-1}\right)$ is the total discharge, and $D_{50}(\mathrm{~m})$ is the median grain diameter. As it is hard to measure mean flow velocity in the field, the application of Eq. (6) really becomes difficult because unit stream power depends on mean flow velocity (Eq. 4). It is, however, easier to measure runoff and therefore flow velocity can be calculated using Eq. (7). Incorporating Eq. (7) into Eq. (6) leads to the following description of transport capacity:

$T_{\mathrm{c}}=0.17 \times 10^{6} \frac{Q^{1.46}}{D_{50^{0.50}}} S^{2.89}$

where $S\left(\mathrm{~m} \mathrm{~m}^{-1}\right)$ is the slope gradient. Figure 6 shows the strong agreement between measured and predicted transport capacity using Eq. (8) when jack-knife technique was applied to the dataset $\left(R^{2}=0.85\right)$. The calculated values of error were ranged from -0.03 to $0.04\left(\mathrm{~kg} \mathrm{~m}^{-1} \mathrm{~s}^{-1}\right)$, which implies that the predicted values of transport capacity are not much deviated from the observed values. This suggests that transport capacity can be directly estimated from total discharge, median grain size, and slope gradient, which are relatively easily measured under field condition. Correspondingly, these findings show that the measurements of flow velocity and flow depth are not needed to estimate sediment transport capacity.

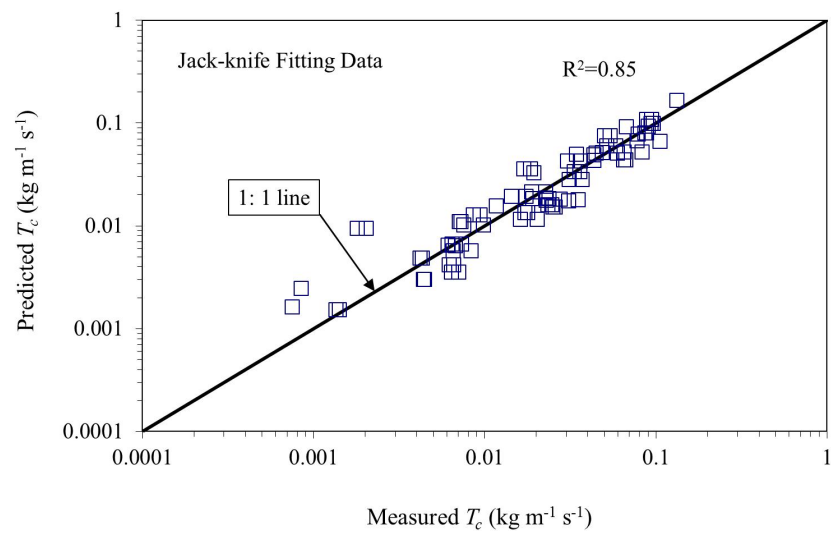

Fig. 6. Comparison between measured and predicted sediment transport capacities by using Eq. (8) when the jack-knife approach is applied.

\section{Conclusions}

The results of this study clearly show that slope gradient has a stronger impact on sediment transport capacity than unit discharge and mean flow velocity. This is most likely due to the fact that the tangential component of the gravity force increases with slope gradient. In addition, because bed geometry varies greatly with slope gradient (Gimenez and Govers, 2001, 2002), the relationships of unit discharge 
and mean flow velocity with transport capacity varied substantially with slope gradient. This indicates that bed form evolution is a feedback mechanism between sediment transport capacity and hydraulic parameters. The results obtained under this study for erodible beds are somewhat different from what the literature shows for non-erodible beds. This is because in case of non-erodible beds, (i) the available flow energy is utilized entirely for sediment transport, instead of dissipating flow energy on bed irregularities, bed form evolution and sediment detachment; and (ii) flow velocity increases steadily with slope gradient.

The experimental results showed that sediment transport capacity is well related to the selected composite force predictors. Unit stream power was the best performing composite predictor for estimation of transport capacity for shallow flows. A weaker relation was obtained between transport capacity and shear stress $\left(R^{2}=0.61\right)$ since part of momentum in overland flow is consumed by form roughness. Despite the fact that stream power and effective stream power are functions of shear stress, both exhibited good potential for prediction of transport capacity, although the exponents of their relationships were found to be dependent on grain size. Among the selected composite predictors, unit stream power is preferred over other composite predictors because (i) grain size has a non-significant effect on the relation between transport capacity and unit stream power, and (ii) mean flow velocity can be easily predicted from total discharge and median grain size (Ali et al., 2012).

Overall, these results are entirely different from the results obtained from experiments with non-erodible beds, because both grain shear stress and form shear stress are utilized for sediment transport in the case of non-erodible beds (Zhang et al., 2009). The derived unit stream power based equation (Eq. 8) shows promise for use in process-based soil erosion models to more precisely estimate sediment transport capacity. More precise estimation of transport capacity is important in the ongoing challenge to better predict and manage soil erosion. The proposed equations should be carefully applied beyond the range of conditions for which it was actually derived, i.e. $0.07 \leq$ unit discharge $\leq 2.07 \times 10^{-3} \mathrm{~m}^{2} \mathrm{~s}^{-1}$, $5.2 \leq S \leq 17.6 \%$ and $0.233 \leq D_{50} \leq 1.022 \mathrm{~mm}$. Nonetheless, the equation suggested from this study was derived for non-cohesive narrowly graded sands, thus its validity needs to be further evaluated for cohesive soils.

Acknowledgements. The experiments were carried out in the Kraaijenhoff van de Leur Laboratory for water and sediment dynamics, Wageningen University, The Netherlands, with the technical assistance and cooperation of Land Degradation and Development Group, whose support is gratefully acknowledged. The authors also like to thank the two anonymous referees, whose comments helped to improve the initial manuscript. The work was financially supported by a grant from the Higher Education Commission, Pakistan (Grant No: 120076).

Edited by: A. Bronstert

\section{References}

Abrahams, A. D. and Li, G.: Effect of saltating sediment on flow resistance and bed roughness in overland flow, Earth Surf. Proc. Land., 23, 953-960, 1998.

Abrahams, A. D., Li, G., and Parsons, A. J.: Rill hydraulics on a semi-arid hillslope, Southern Arizona, Earth Surf. Proc. Land. 21, 35-47, 1996.

Abrahams, A. D., Li, G., Krishana, C., and Atkinson, J. F.: A sediment transport equation for interrill overland flow on rough surface, Earth Surf. Proc. Land., 26, 1443-1459, 2001.

Ali, M.: Sediment transport capacity for soil erosion modelling at hillslope scale: an experimental approach, Ph.D. thesis, Wageningen University, The Netherlands, 120 pp., 2012.

Bagnold, R. A.: An approach to the sediment transport problem from general physics, United States Geological Survey Professional Paper: 422-I, 1966.

Beasley, D. B. and Huggins, L. F.: ANSWERS user's manual, Department of agricultural engineering, Purdue University, West Lafayette, IN, 1982.

Chorley, R. J., Schumm, S. A., and Sugden, D. E.: Geomorphology, Methuen, London, 1984.

De Roo, A. P. J., Offermans, R. J. E., and Cremers, N. H. D. T.: LISEM: A single event physically based hydrological and soil erosion model for drainage basin II: sensitivity analysis, validation and application, Hydrol. Process., 10, 1119-1126, 1996.

DuBoys, M. P.: Le Rhône et les rivières à lit afflouillable, Annals de Ponts et Chaussée, 18, 141-195, 1879.

Dunkerley, D.: Estimating the mean speed of laminar overland flow using dye injection-uncertainty on rough surfaces, Earth Surf. Proc. Land., 26, 363-374, 2001.

Elliot, W. J. and Laflen, J. M.: A process-based rill erosion model, T. Am. Soc. Agr. Eng., 36, 35-72, 1993.

Everaert, W.: Empirical relations for the sediment transport capacity of interrill flow, Earth Surf. Proc. Land., 16, 513-532, 1991.

Ferro, V.: Evaluating overland flow sediment transport capacity, Hydrol. Process., 12, 1895-1910, 1998.

Finkner, S. C., Nearing, M. A., Foster, G. R., and Gilley, J. E.: A simplified equation for modeling sediment transport capacity, T. Am. Soc. Agr. Eng., 32, 1545-1550, 1989.

Flanagan, D. C., Ascough, J. C., Nearing, M. A., and Laflen, J. M.: The water erosion prediction project (WEPP) model, in: Landscape Erosion and Evolution Modelling, edited by: Harmon, R. S. and Doe, W. W., Kluwer Academics/Plenum, New York, 145199, 2001.

Foster, G. R.: Modeling the erosion process, in: Hydrologic Modeling of Small Watersheds, edited by: Hahn, C. T., Jonson, H., and Brakensiek, D., American Society of Agricultural Engineers, St. Joseph, MI, 295-380, 1982.

Foster, G. R. and Meyer, L. D.: Transport of soil particles by shallow flow, T. Am. Soc. Agr. Eng., 15, 99-102, 1972.

Foster, G. R., Huggins, L. F., and Meyer, L. D.: A laboratory study of rill hydraulics, I, Velocity relationship, T. Am. Soc. Agr. Eng., 27, 790-796, 1984.

Gimenez, R. and Govers, G.: Interaction between bed roughness and flow hydraulics in eroding rills, Water Resour. Res., 37, 791799, 2001.

Gimenez, R. and Govers G.: Flow detachment by concentrated flow on smooth and irregular beds, Soil Sci. Soc. Am. J., 66, 14751483, 2002. 
Golden Software: Surface Mapping System, version 8.05, Golden Software, Inc., Golden, Co USA, 2004.

Govers, G.: Empirical relationships on the transporting capacity of overland flow, Transport and Deposition Processes, Proceedings of the Jerusalem Workshop, March-April 1987, IAHS, 189, 4563, 1990.

Govers, G.: Evaluation of transporting capacity formulae for overland flow, in: Overland Flow Hydraulics and Erosion Mechanics, edited by: Parsons, A. J. and Abrahams, A. D., University College London Press, London, 243-273, 1992.

Govers, G. and Rauws, G.: Transporting capacity of overland flow on plane and on irregular beds, Earth Surf. Proc. Land., 11, 515$524,1986$.

Guy, B. T., Dickinson, W. T., and Rudra, R. P.: The roles of rainfall and runoff in the sediment transport capacity of interrill flow, T. Am. Soc. Agr. Eng., 30, 1378-1386, 1987.

Guy, B. T., Dickinson, W. T., Rudra, R. P., and Wall, G. J.: Hydraulics of sediment-laden sheetflow and the influence of simulated rainfall, Earth Surf. Proc. Land., 15, 101-118, 1990.

Hu, S. X. and Abrahams, A. D.: Partitioning resistance to overland flow on rough mobile beds, Earth Surf. Proc. Land., 31, 12801291, 2006.

Jayawardena, A. W. and Bhuiyan, R. R.: Evaluation of an interrill soil erosion model using laboratory catchment data, Hydrol. Process., 13, 89-100, 1999.

Julien, P. Y. and Simons, D. B.: Sediment transport capacity of overland flow, T. Am. Soc. Agr. Eng., 28, 755-762, 1985.

Lal, R.: Soil erosion impact on agronomic productivity and environment quality, Crit. Rev. Plant Sci., 17, 319-464, 1998.

Lei, T. W., Nearing, M. A., Haghighi, K., and Bralts, V. F.: Rill erosion and morphological evolution: A simulation model, Water Resour. Res., 34, 3157-3168, 1998.

Lei, T. W., Zhang, Q., Zhao, J., and Tang, Z.: A laboratory study of sediment transport capacity in the dynamic process of rill erosion, T. Am. Soc. Agr. Eng., 44, 1537-1542, 2001.

Lu, J. Y., Cassol, E. A., and Moldenhauer, W. C.: Sediment transport relationships for sand and silt loam soils, T. Am. Soc. Agr. Eng., 32, 1923-1931, 1989.

Merten, G. H., Nearing, M. A., and Borges, A. L. O.: Effect of sediment load on soil detachment and deposition in rills, Soil Sci. Soc. Am. J., 65, 861-868, 2001.

Moore, I. D. and Burch, G. J.: Sediment transport capacity of sheet and rill flow: application of unit stream power theory, Water Resour. Res., 22, 1350-1360, 1986.
Morgan, R. P. C., Quinton, J. N., Smith, R. E., Govers, G., Poesen, J., Auerswald, K., Chisci, G., Torri, D., and Styczen, M. E.: The European Soil Erosion Model (EUROSEM): A dynamic approach for predicting sediment transport from fields and small catchments, Earth Surf. Proc. Land., 23, 527-544, 1998.

Nearing, M. A., Norton, L. D., Bulgakov, D. A., and Larionov, G. A.: Hydraulics and erosion in eroding rills, Water Resour. Res., 33, 865-876, 1997.

Nearing, M. A., Simanton, J. R., Norton, L. D., Bulygin, S. J., and Stone, J.: Soil erosion by surface water flow on a stony, semiarid hillslope, Earth Surf. Proc. Land., 24, 677-686, 1999.

Prosser, I. and Rustomji, P.: Sediment transport capacity relations for overland flow, Prog. Phys. Geogr., 24, 179-193, 2000.

Smith, R. E., Goodrich, D. C., and Quinton, J. N.: Dynamic, distributed simulation of watershed erosion: the KINEROS2 and EUROSEM models, J. Soil Water Conserv., 50, 517-520, 1995.

Takken, I., Govers, G., Ciesiolka, C. A. A., Silburn, D. M., and Loch, R. J.: Factors influencing the velocity-discharge relationship in rills, in: Proceedings for the International Symposium on Modelling Soil Erosion, Sediment Transport and Closely Related Hydrological Processes, Vienna, 1998, IAHS Publ., 249, 63-70, 1998.

Wei, H., Nearing, M. A., Stone, J. J., Guertin, D. P., Spaeth, K. E., Pierson, F. B., Nichols, M. H., and Moffet, C. A.: A new splash and sheet erosion equation for rangelands, Soil Sci. Soc. Am. J., 73, 1386-1392, 2009.

Yang, C. T.: Unit stream power and sediment transport, J. Hydraul. Div., 98, 1805-1826, 1972.

Zhang, G., Liu, B., Han, Y., and Zhang, X.C.: Sediment transport and soil detachment on steep slopes: I. transport capacity estimation, Soil Sci. Soc. Am. J., 73, 1291-1297, 2009.

Zhang, G., Shen, R., Luo, R., Cao, Y., and Zhang, X. C.: Effects of sediment load on hydraulics of overland flow on steep slopes, Earth Surf. Proc. Land., 35, 1811-1819, 2010a.

Zhang, G., Luo, R., Cao, Y., Shen, R., and Zhang, X. C.: Correction factor to dye-measured flow velocity under varying water and sediment discharges, J. Hydrol., 389, 205-213, 2010 b.

Zhang, G., Luo, R., Cao, Y., Shen, R., and Zhang, X. C.: Impacts of sediment load on Manning coefficient in supercritical shallow flow on steep slopes, Hydrol. Process., 24, 3909-3914, 2010 c. 